\title{
Excellent field emission properties from carbon nanotube field emitters fabricated using a filtration-taping method
}

\author{
Dong Hoon Shin ${ }^{1}$, Seung II Jung ${ }^{1}$, Ki Nam Yun ${ }^{1}$, Guohai Chen ${ }^{2}$, Seok-Gy Jeon ${ }^{3}$, Jung-II Kim ${ }^{3}$ and Cheol Jin Lee ${ }^{1, *}$ \\ ${ }^{1}$ School of Electrical Engineering, Korea University, Seoul 136-713, Korea \\ ${ }^{2}$ National Institute of Advanced Industrial Science and Technology, Tsukuba, Ibaraki 305-8565, Japan \\ ${ }^{3}$ Advanced Medical Device Research Center, Korea Electrotechnology Research Institute, Ansan 426-170, Korea
}

\section{Article Info \\ Received 23 June 2014 \\ Accepted 12 July 2014 \\ *Corresponding Author \\ E-mail: cjlee@korea.ac.kr}

\section{Open Access}

DOI: http://dx.doi.org/

10.5714/CL.2014.15.3.214

This is an Open Access article distributed under the terms of the Creative Commons Attribution Non-Commercial License (http://creativecommons.org/licenses/ by-nc/3.0/) which permits unrestricted non-commercial use, distribution, and reproduction in any medium, provided the original work is properly cited.

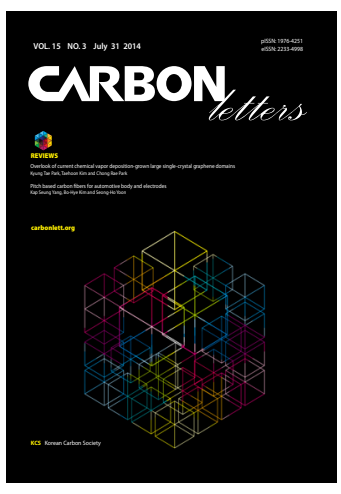

http://carbonlett.org

pISSN: $1976-4251$

elSSN: 2233-4998

Copyright $\odot$ Korean Carbon Society

\begin{abstract}
A filtration-taping method was demonstrated to fabricate carbon nanotube (CNT) emitters. This method shows many good features, including high mechanical adhesion, good electrical contact, low temperature, organic-free, low cost, large size, and suitability for various CNT materials and substrates. These good features promise an advanced field emission performance with a turn-on field of $0.88 \mathrm{~V} / \mu \mathrm{m}$ at a current density of $0.1 \mu \mathrm{A} / \mathrm{cm}^{2}$, a threshold field of $1.98 \mathrm{~V} / \mu \mathrm{m}$ at a current density of $1 \mathrm{~mA} / \mathrm{cm}^{2}$, and a good stability of over $20 \mathrm{~h}$. The filtration-taping technique is an effective way to realize low-cost, large-size, and high-performance CNT emitters.
\end{abstract}

Key words: field emission properties, carbon nanotube, filtration-taping method

\section{Introduction}

Due to their unique geometry and physical properties, carbon nanotubes (CNTs) are currently being investigated as next-generation field emitter materials for cold cathodes. Numerous papers can be found on field emission applications such as field emission displays, lamps, X-ray sources, high-resolution electron-beam instruments, and microwave amplifiers [1-5]. Up to now, various techniques have been developed for fabricating CNT field emitters using as-grown, spraying, electrophoresis, screen-printing, and attaching individual CNTs on tungsten probe methods, etc. [6-10]. However, these techniques suffer from weak mechanical adhesion between CNT emitters and the cathode, or severe degradation of CNT emitters due to the organic binders used in the process, which lead to a short lifetime. Therefore, an efficient and organic binder-free technique for fabricating CNT emitters is still a great challenge. In this letter, we demonstrate an advanced organic-free technique named the filtration-taping method. The filtration-taping method is suitable to fabricate simple, large, and cost-effective CNT emitters that can ensure a high mechanical adhesion, good electrical contact, and damage-free CNT tips, resulting in enhanced field emission properties and excellent stability.

\section{Experimental}

The fabrication procedure of the filtration-taping method is as follows. A uniform CNT film was formed onto a filter membrane using a vacuum ambient to filter a suspension of highly-dispersed CNTs $[11,12]$. Then, the CNT film was transferred to one side of a doublesided conductive tape (MAINELECOM, Ltd., the surface resistance is less than $4 \mathrm{~m} \Omega / \mathrm{mm}^{2}$ ) by pressing the membrane facing down on the tape. A circular disk with dimensions of $5 \mathrm{~mm}$ in diameter and $1 \mathrm{~mm}$ in thickness was attached onto the center of a stainless steel plate to 
(a)
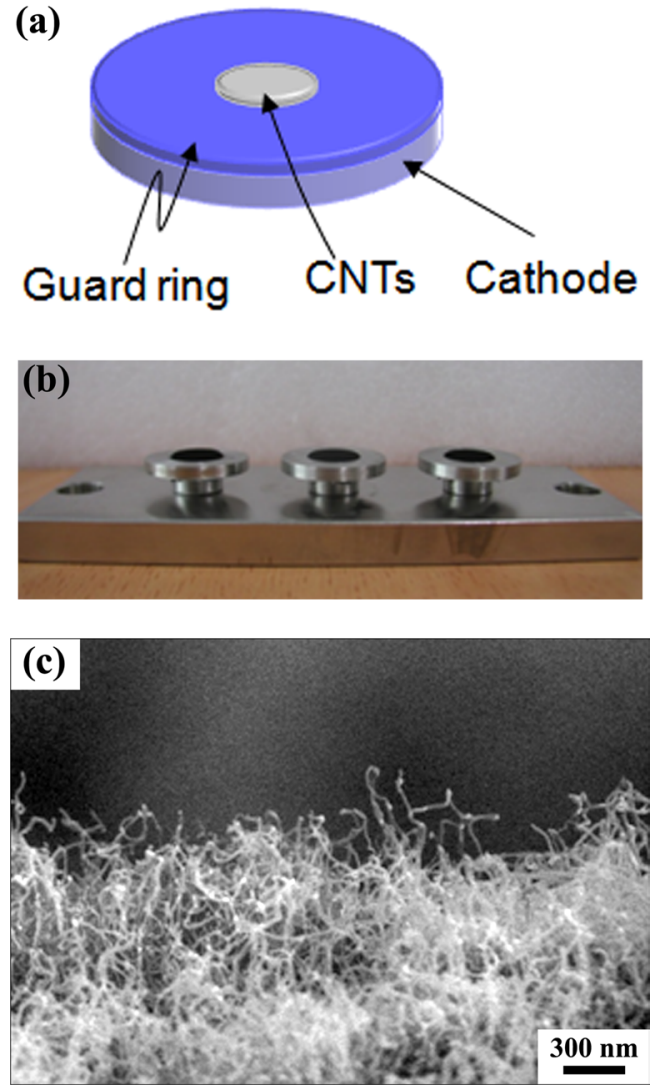

Fig. 1. (a) The schematic of the carbon nanotube (CNT) emitter finished with a guard-ring, exposing the center CNT region as the cathode. (b) A photograph of three real CNT field emitters fabricated by the filtrationtaping method. (c) Scanning electron microscopy image of a thin multiwalled CNT field emitter fabricated by the filtration-taping method.

form the cathode. The edge of the circular disk was ground to avoid edge emission [13]. Then, the conductive adhesive tape with CNT film faced up was set on the protruded circular disk. Finally, a $0.5 \mathrm{~mm}$-thick stainless steel guard ring with a hole of $5 \mathrm{~mm}$ diameter pierced in the center was put on, only exposing CNTs in the center region to act as the emitter, as shown in Fig. 1a. Fig. 1b shows three real CNT field emitters using the filtration-taping method, indicating a very simple but efficient technique.

It is worth noting that our emitter fabrication technique can be applicable to all types of CNT materials, including single-walled CNTs (SWCNTs), double-walled CNTs (DWCNTs), thick and thin multi-walled CNTs (MWCNTs). Since the same fabrication technique can be used for various CNT materials freely, it is possible for us to compare the performance of various types of CNT materials exactly. In this work, thin-MWCNTs were used because they can possess the merits of both SWCNTs (DWCNTs) and thick-MWCNTs due to their several concentric graphene layers. The morphology of the thin-MWCNT field emitter was characterized by scanning electronic microscopy (SEM, Hitachi, S-4700) and is shown in Fig. 1c. It can be seen that there are numerous vertically-aligned CNTs protruding from the substrate surface. It is well known that the vertically aligned CNTs can exhibit a better field emission performance than the randomlyoriented CNTs [6]. This is an important feature of the filtrationtaping method. However, other methods, such as spraying, electrophoresis, and screen-printing, usually obtain randomlyoriented CNTs. Most of the CNTs are lying down, and hence, only a few protruding CNTs can participate in the field emission $[14,15]$. Accordingly, the special post-treatments, like soft rubber rolling, laser treatment, electrical annealing, thermal oxidation, argon irradiation, ultraviolet laser ablation, and adhesive taping, are needed to activate the randomly-oriented CNT emitters or remove some possible contamination [15-21]. But for the filtration-taping technique, CNTs are aligned during a transfer procedure when we separate the CNT film from the filter membrane. As a result, the filtration-taping technique demonstrates a simple and efficient method to fabricate the CNT emitters with excellent field emission properties.

The screen-printing and spraying methods are typically used to fabricate CNT emitters. In this work, we compared the field emission properties from the thin-MWCNT emitters using the three different fabrication techniques. The field emission measurement was performed using a planar diode configuration in a vacuum chamber at a pressure of $2 \times 10^{-7}$ torr. The anode was a stainless steel plate. The gap between the cathode and the anode was adjusted to $400 \mu \mathrm{m}$. The same amount of thin-MWCNTs was used to obtain the field emitters.

\section{Results and Discussion}

The field emission characteristics from thin-MWCNT emitters fabricated by filtration-taping, screen-printing, and spraying methods are shown in Fig. 2a. The CNT emitter fabricated by the filtration-taping method demonstrates the best field emission performance: the lowest turn-on electric field of $0.88 \mathrm{~V} /$ $\mu \mathrm{m}$ at an emission current density of $0.1 \mathrm{~A} / \mathrm{cm}^{2}$ and a threshold electric field of $1.98 \mathrm{~V} / \mu \mathrm{m}$ at an emission current density of 1 $\mathrm{mA} / \mathrm{cm}^{2}$, and the largest field enhancement factor of 3337 . The achieved field emission performance is much higher than those of the previous results $[8,22-24]$. We consider that the largest field enhancement factor also confirms the vertical alignment of CNTs in the filtration-taping field emitter. In addition, a very high emission current density can be obtained using the filtration-taping method. As shown in Fig. 2b, an emission current density of $500 \mathrm{~mA} / \mathrm{cm}^{2}$ is obtained at the applied electric field of $3.28 \mathrm{~V} / \mu \mathrm{m}$ from a $5 \mathrm{~mm}$-diameter CNT emitter with a gap of $400 \mu \mathrm{m}$. The higher emission current density can be achieved if the higher power supply is available. However, we can only obtain the emission current density of $90 \mathrm{~mA} / \mathrm{cm}^{2}$ from the CNT emitter using the typical spraying technique. We attribute the excellent performance of the high emission current from the CNT emitter fabricated by the filtration-taping technique to the following advantages of the filtration-taping method: the high density of emission sites at the CNT emitter, the good electrical contact, the strong mechanical adhesion between CNTs and the cathode, and the low degradation of CNT tips due to the organicfree process. In addition, during the field emission measurement, arcing was usually observed under a high electric field from the CNT emitters fabricated by the screen-printing or the spraying methods whereas it was very rare from the CNT emitters fabri- 

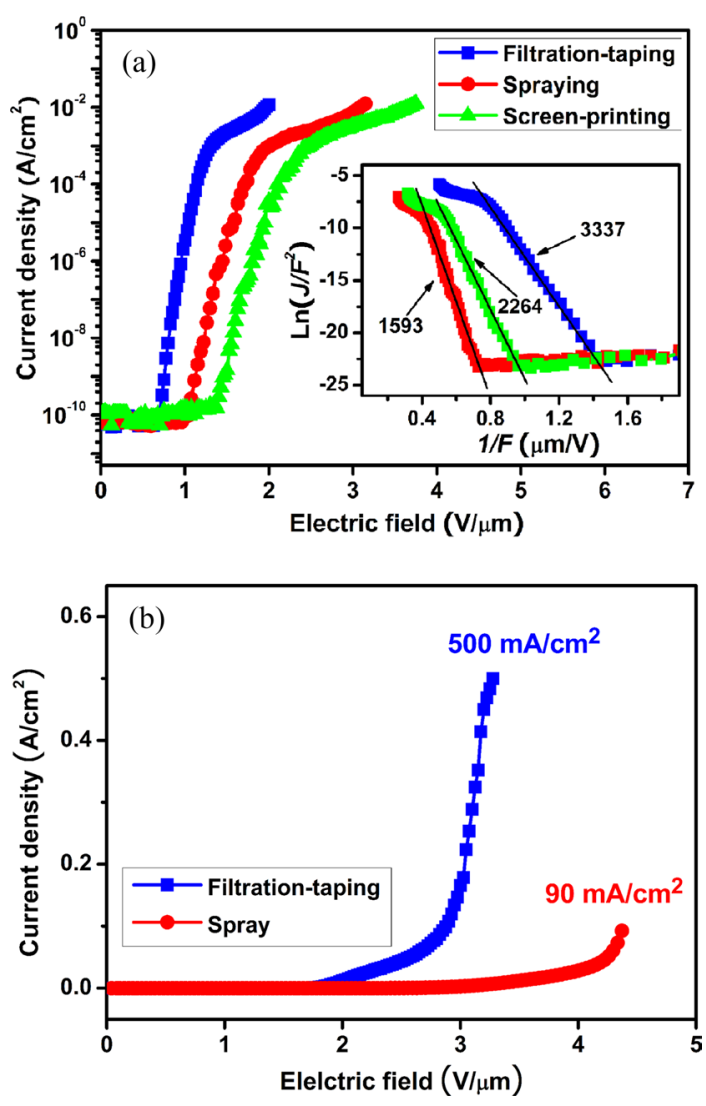

Fig. 2. Comparison of the field emission properties using different fabrication methods. (a) Field emission characteristics from the thin multiwalled carbon nanotube (MWCNT) emitters fabricated by filtration-taping, spraying, and screen-printing methods. The inset shows the corresponding F-N plots. (b) A high field emission current density of $500 \mathrm{~mA} / \mathrm{cm}^{2}$ was obtained from the thin-MWCNT emitter fabricated by the filtration-taping method at a gap of $3.28 \mathrm{~V} / \mu \mathrm{m}$. Comparatively, the highest current density achieved from the thin-MWCNT emitter fabricated by the spraying method is only $90 \mathrm{~mA} / \mathrm{cm}^{2}$.

cated by the filtration-taping method.

A bright image of electron emission pattern observed from a rectangular thin-MWCNT emitter with a large size of $5 \times 4$ $\mathrm{cm}^{2}$ is shown in Fig. 3a. The electron emission pattern was investigated using a phosphor-coated conducting indium tin oxide (ITO) glass as the anode. The gap and the applied voltage between the cathode and the anode were $3 \mathrm{~mm}$ and $3600 \mathrm{~V}$, respectively. The thin-MWCNT emitter shows a uniform emission pattern and a high density of emission sites across the whole emitter region of $5 \times 4 \mathrm{~cm}^{2}$. The dark image in the left bottom inset of Fig. 3a also confirms the uniform emission sites of the large size field emitter. The field emission stability is also a very important parameter for the practical application of the CNT field emitters. We evaluated the emission stability of the large size thin-MWCNT emitter. The initial emission current density was set at 0.18 $\mathrm{mA} / \mathrm{cm}^{2}$. The thin-MWCNT emitter shows a very stable emission behavior with only $12.8 \%$ current degradation after $20 \mathrm{~h}$, as shown in Fig. 3b, indicating that the filtration-taping method can provide excellent emission stability. Due to the degradation of the ITO glass, we also investigated the field emission stability
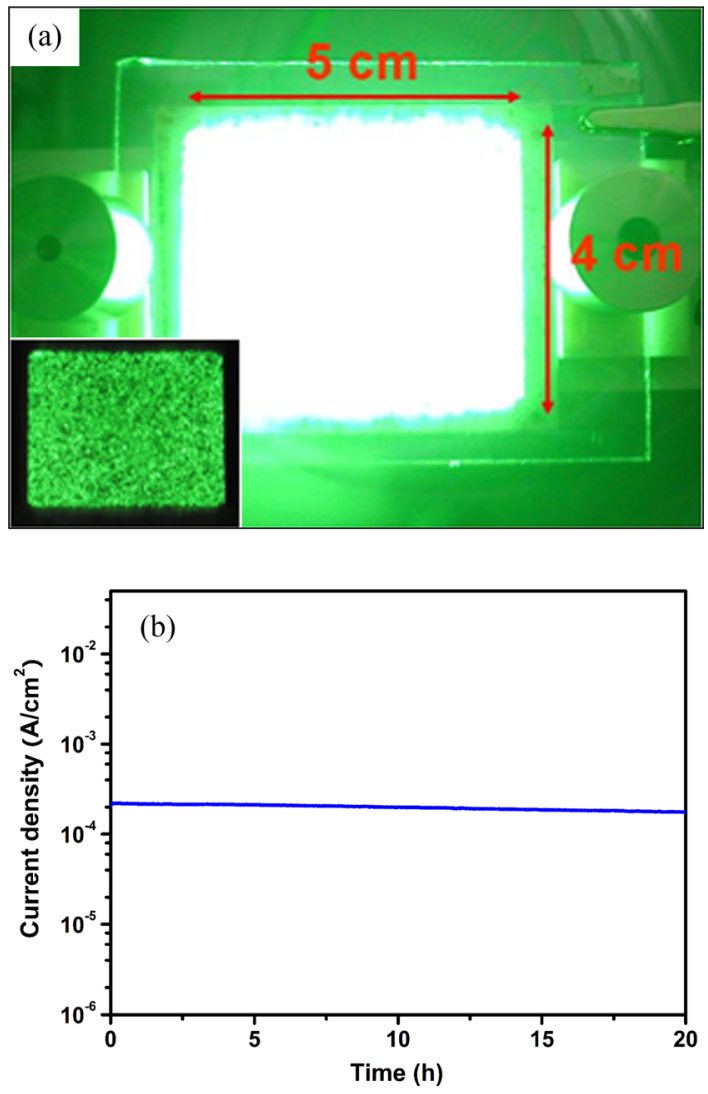

Fig. 3. (a) A bright image of the uniform emission pattern observed from a thin multi-walled carbon nanotube (MWCNT) emitter with a large size of $5 \times 4 \mathrm{~cm}^{2}$. The left bottom inset shows the corresponding dark image. (b) Field emission stability of the large size thin-MWCNT emitter with $5 \times 4 \mathrm{~cm}^{2}$ area showed $12.8 \%$ degradation after $20 \mathrm{~h}$ at an initial current density of $0.18 \mathrm{~mA} / \mathrm{cm}^{2}$, indicating a very stable emitter.

using a $5 \mathrm{~mm}$-diameter emitter and a stainless steel plate as the anode and accordingly obtained an excellent stability with $20 \%$ current degradation for $20 \mathrm{~h}$ from an initial emission current density of $1 \mathrm{~mA} / \mathrm{cm}^{2}$, which is a very severe acceleration lifetime test condition. We attribute the remarkable field emission stability to other good features of the filtration-taping method, i.e. the high mechanical adhesion between CNTs and the cathode and no contamination of CNT tips from harmful organic materials by adapting the organic-free process. Higher mechanical adhesion can permit CNT emitters sustainable on the cathode under the higher applied electric field so as to avoid being pulled out. In addition, the out-gassing from the organic materials is one of the main reasons for CNT degradation and vacuum deterioration, resulting in degradation of emission performance. For the conventional screen-printing method, some organic vehicles are used to fabricate CNT emitters, and they exist partially at the CNT emitters after removing the organic materials. Therefore, at the high electric field region, the ion bombardment of residual gases, which originate from the organic materials can destroy or modify the structure of CNT emitters, consequently reducing the emission current and stability [8]. However, the filtration-taping technique is an organic-free process so that the damage of the CNT emitters can be effectively avoided or alleviated. 


\section{Conclusion}

In summary, we demonstrated a simple but efficient fabrication method for CNT emitters known as the filtration-taping technique. The following advanced field emission properties could be achieved from the filtration-taping CNT emitters: a low turnon field of $0.88 \mathrm{~V} / \mathrm{m}$, a low threshold filed of $1.98 \mathrm{~V} / \mu \mathrm{m}$, a high emission current density of $500 \mathrm{~mA} / \mathrm{cm}^{2}$, and good stability. We attribute the excellent field emission performance to the organicfree process and the simple contact-transfer process, which are the newly designed filtration-taping method. We strongly suggest that the filtration-taping technique is an effective way to realize lowcost, large-size, and high-performance CNT emitters.

\section{Acknowledgements}

This work was supported by the World Class University (WCU, R32-2008-000-10082-0) Project through the Korea Science and Engineering Foundation funded by the Ministry of Education, Science and Technology and the Korea Basic Science Institute.

\section{References}

[1] de Heer WA, Châtelain A, Ugarte D. A carbon nanotube fieldemission electron source. Science, 270, 1179 (1995). http://dx.doi. org/10.1126/science.270.5239.1179.

[2] Saito Y, Uemura S. Field emission from carbon nanotubes and its application to electron sources. Carbon, 38, 169 (2000). http:// dx.doi.org/10.1016/S0008-6223(99)00139-6.

[3] de Jonge N, Lamy Y, Schoots K, Oosterkamp TH. High brightness electron beam from a multi-walled carbon nanotube. Nature, $\mathbf{4 2 0}$, 393 (2002). http://dx.doi.org/10.1038/nature01233.

[4] Liu ZJ, Yang G, Lee YZ, Bordelon D, Lu JP, Zhou O. Carbon nanotube based microfocus field emission $\mathrm{x}$-ray source for microcomputed tomography. Appl Phys Lett, 89, 103111 (2006). http://dx.doi.org/10.1063/1.2345829.

[5] Yabushita R, Hata K. Development of high spatial resolution x-ray radiography system equipped with multiwalled carbon nanotube field emission cathode. J Vac Sci Technol B, 26, 702 (2008). http:// dx.doi.org/10.1116/1.2894879.

[6] Chen G, Shin DH, Iwasaki T, Kawarada H, Lee CJ. Enhanced field emission properties of vertically aligned double-walled carbon nanotube arrays. Nanotechnology, 19, 415703 (2008). http:// dx.doi.org/10.1088/0957-4484/19/41/415703.

[7] Ren ZF, Huang ZP, Xu JW, Wang JH, Bush P, Siegal MP, Provencio PN. Synthesis of large arrays of well-aligned carbon nanotubes on glass. Science, 282, 1105 (1998). http://dx.doi.org/10.1126/science.282.5391.1105

[8] Choi WB, Chung DS, Kang JH, Kim HY, Jin YW, Han IT, Lee YH, Jung JE, Lee NS, Park GS, Kim JM. Fully sealed, high-brightness carbon-nanotube field-emission display. Appl Phys Lett, 75, 3129 (1999). http://dx.doi.org/10.1063/1.125253.

[9] Gao B, Yue GZ, Qiu Q, Cheng Y, Shimoda H, Fleming L, Zhou O. Fabrication and electron field emission properties of carbon nanotube films by electrophoretic deposition. Adv Mater, 13, 1770 (2001). http://dx.doi.org/10.1002/1521-4095(200112)13:23<1770::AID-
ADMA1770>3.0.CO;2-G.

[10] Jung SI, Choi JS, Shim HC, Kim S, Jo SH, Lee CJ. Fabrication of probe-typed carbon nanotube point emitters. Appl Phys Lett, 89, 233108 (2006). http://dx.doi.org/10.1063/1.2402222.

[11] Chun KY, Choi SK, Kang HJ, Park CY, Lee CJ. Highly dispersed multi-walled carbon nanotubes in ethanol using potassium doping. Carbon, 44, 1491 (2006). http://dx.doi.org/10.1016/j.carbon.2005.12.004.

[12] Wu ZC, Chen ZH, Du X, Logan JM, Sippel J, Nikolou M, Kamaras K, Reynolds JR, Tanner DB, Hebard AF, Rinzler AG. Transparent conductive carbon nanotube films. Science, 305, 1273 (2004). http://dx.doi.org/10.1126/science.1101243.

[13] Fujii S, Honda S, Machida H, Kawai H, Ishida K, Katayama M, Furuta H, Hirao T, Oura K. Efficient field emission from an individual aligned carbon nanotube bundle enhanced by edge effect. Appl Phys Lett, 90, 153108 (2007). http://dx.doi. org/10.1063/1.2721876.

[14] Chhowalla M, Ducati C, Rupesinghe NL, Teo KBK, Amaratunga GAJ. Field emission from short and stubby vertically aligned carbon nanotubes. Appl Phys Lett, 79, 2079 (2001). http://dx.doi. org/10.1063/1.1406557.

[15] Zeng BQ, Xiong GY, Chen S, Wang WZ, Wang DZ, Ren ZF. Enhancement of field emission of aligned carbon nanotubes by thermal oxidation. Appl Phys Lett, 89, 223119 (2006). http:// dx.doi.org/10.1063/1.2399342.

[16] Kim YC, Sohn KH, Cho YM, Yoo EH. Vertical alignment of printed carbon nanotubes by multiple field emission cycles. App Phys Lett, 84, 5350 (2004). http://dx.doi.org/10.1063/1.1766403.

[17] Chen KF, Chen KC, Jiang YC, Jiang LY, Chang YY, Hsiao MC, Chan LH. Field emission image uniformity improvement by laser treating carbon nanotube powders. Appl Phys Lett, 88, 193127 (2006). http://dx.doi.org/10.1063/1.2203206.

[18] Liang XH, Deng SZ, Xu NS, Chen J, Huang NY, She JC. On achieving better uniform carbon nanotube field emission by electrical treatment and the underlying mechanism. Appl Phys Lett, 88, 111501 (2006). http://dx.doi.org/10.1063/1.2180439.

[19] Weng CH, Leou KC, Wei HW, Juang ZY, Wei MT, Tung CH, Tsai $\mathrm{CH}$. Structural transformation and field emission enhancement of carbon nanofibers by energetic argon plasma post-treatment. Appl Phys Lett, 85, 4732 (2004). http://dx.doi.org/10.1063/1.1815062.

[20] Kim JS, Ahn KS, Kim CO, Hong JP. Ultraviolet laser treatment of multiwall carbon nanotubes grown at low temperature. Appl Phys Lett, 82, 1607 (2003). http://dx.doi.org/10.1063/1.1559654.

[21] Vink TJ, Gillies M, Kriege JC, van de Laar HWJJ. Enhanced field emission from printed carbon nanotubes by mechanical surface modification. Appl Phys Lett, 83, 3552 (2003). http://dx.doi. org/10.1063/1.1622789.

[22] Jeong HJ, Choi HK, Kim GY, Song YI, Tong Y, Lim SC, Lee YH Fabrication of efficient field emitters with thin multiwalled carbon nanotubes using spray method. Carbon, 44, 2689 (2006). http:// dx.doi.org/10.1016/j.carbon.2006.04.009.

[23] Qian C, Qi H, Gao B, Cheng Y, Qiu Q, Qin LC, Zhou O, Liu J. Fabrication of small diameter few-walled carbon nanotubes with enhanced field emission property. J Nanosci Nanotechnol, 6, 1346 (2006). http://dx.doi.org/10.1166/jnn.2006.140.

[24] Moon JS, Alegaonkar PS, Han JH, Lee TY, Yoo JB, Kim JM. Enhanced field emission properties of thin-multiwalled carbon nanotubes: role of $\mathrm{SiO}_{\mathrm{x}}$ coating. J Appl Phys, 100, 104303 (2006). http://dx.doi.org/10.1063/1.2384795. 